\title{
Políticas públicas para a educação do campo: legislação, implementação e avaliação
}

\author{
Public politics for field education: legislation, implementation and evaluation \\ Politiques publiques pour l'education sur le terrain: législation, mise en oeuvre et évaluation
}

\author{
Zilmar Santos Cardoso ${ }^{1}$ \\ Universidade Estadual de Montes Claros
}

\begin{abstract}
Resumo: Com o presente texto apresentamos uma breve reflexão sobre a dicotomia entre a educação rural e a Educação do Campo, tomando como referencial as políticas públicas educacionais para a Educação do Campo. Discutimos o histórico contexto de ausência da educação voltada para a população campesina na legislação brasileira, especificamente nos marcos legais educacionais, bem como, o contex to de criação e significado da Educação do Campo, como resultado das reivindicações dos movimentos sociais em prol de uma educação voltada para a realidade da vida do campo.
\end{abstract}

Palavras-Chave: Educação Rural. Educação do Campo. Políticas Públicas. Legislação Brasileira.

Abstract: With this text we present a brief reflexion about the dichotomy between rural education and educacion in the fiel, takink, as a reference the public educacional politics for the educacion of the field. We discussed the historical context of absence of education focused on the Brazilian legislation campesina population, specificallyin legal education, as well as the context of creation and meaning of education field, as a result of the claims of social movements in favor of an education geared to the reality of the life of the field.

Keywords: Rural Education. The Education Field. Public Politics. Brazilian Legislation.

Résumé: Avec le présent texte, nous présentons une brève réflexion sur la dichotomie entre l'éducation rurale et l'éducation de terrain, en prenant comme référence les politiques publiques éducatives pour l'éducation de terrain. Nous discutons du contexte historique de l'absence d'éducation paysanne dans la législation brésilienne, en particulier dans les cadres juridiques éducatifs, ainsi que du contexte de la création et de la signification de l'éducation de terrain, à la suite des revendications des mouvements sociaux pour l'éducation. la réalité de la vie rurale.

Mots-clés: Education rurale. Éducation de terrain. Politiques publiques. Législation brésilienne.

\footnotetext{
${ }^{1}$ Professora do Departamento de Educação/Unimontes. Doutora em Ciências Sociais pela Universidade Estadual do Rio de Janeiro. E-mail.zilmar.cardoso@ead.unimontes.br.
} 


\section{Introdução}

Nesse trabalho de cunho bibliográfico, apresentamos uma visão da evolução da concepção de Educação Rural para a Educação do Campo, discutindo a legislação e o percurso da implementação e avaliação das políticas públicas para a educação da população campesina. Assim, num primeiro momento apresentamos um percurso panorâmico da Educação Rural nas Constituições Brasileiras, traçando o histórico contex to de ausência de ações do Poder Público em prol da educação voltada para a população campesina, evidenciando o processo de criação e significação da Educação do Campo, como resultado das reivindicações dos movimentos sociais por uma educação voltada para realidade da vida do campo. Na sequência, discutimos como a educação do meio rural vem sendo tratada na atual Lei de Diretrizes e Bases da Educação - LDB (BRASIL, 1996), buscando evidenciar a responsabilidade atribuída ao Estado desde a primeira LDB até a atual. E por fim, analisamos o processo de implementação e avaliação das políticas públicas voltadas para a população do campo, utilizando-nos da teoria da constituição de políticas públicas de Azevedo (2007).

\section{Panorama histórico da Educação do Campo a partir das Constituições Brasileiras}

Em qualquer área, as políticas públicas originam-se, majoritariamente, das reivindicações sociais. Assim é a Educação do Campo, uma política educacional recente no Brasil, fruto da organização e reivindicação dos movimentos sociais, em especial do Movimento dos Trabalhadores Rurais Sem Terra (MST).

Para a implantação de uma política pública estatal, a deliberação legislativa é fundamental dado que ela determina a responsabilidade do Estado e dos órgãos públicos, e outros sujeitos/instituições, no cumprimento do estabelecido. No caso da educação destinada à população do campo, no que tange à legislação, tem-se o registro de um histórico de descaso desse poder público e estatal. As primeiras Constituições Brasileiras deixaram de fora de seus textos a Educação Rural, e somente no texto da $3^{\text {a }}$ Constituição do Brasil, em 1934, encontramos no art. 156 a primeira referência para a Educação Rural, assegurando seu financiamento por meios de recursos provenientes da União e vagas orientações no art. 121 sobre a forma de oferta de educação para população rural (BRASIL, 1934).

Com a expansão da indústria, nos anos 1937, uma nova Constituição é aprovada, valorizando a importância da educação profissional, estabelecendo que as indústrias deveriam 
criar escolas de aprendizes destinadas aos filhos dos operários e ainda responsabilizando o Estado a criar ou auxiliar instituições, com o objetivo de proporcionar aos jovens períodos de trabalho no campo.

Na Constituição de 1946, é reforçada a gratuidade para instrução no ensino primário. No entanto, responsabiliza-se as empresas privadas, incluindo aqui as agrícolas, a garantia do custeio dessa escolarização, estabelecendo no inciso III, do art. 168, que as empresas que contassem com mais de cem funcionários, deveriam garantir o ensino primário gratuito para os funcionários e seus filhos (BRASIL, 1946). No entanto, assim como na Constituição de 1937, os textos das Constituições de 1946 e 1967 determinavam esta exigência para as indústrias com mais de cem funcionários, mas ao mesmo tempo, estabeleciam que estas orientações não prevaleciam para as indústrias agrícolas. Assim, nas empresas com atividades eminentemente agrícolas, os funcionários e seus filhos não tinham os mesmos direitos educacionais que eram assegurados nas empresas industriais e comerciais.

Nesse contexto, observamos uma distinção econômica e social entre a vida urbana e a vida rural. Sobre essa visão reducionista e excludente, Acilino e Lucini (2007, p. 178) apontam que havia “[ [...] um imaginário de que, para viver na roça, não há necessidade de amplos conhecimentos socializados pela escola. Essa concepção de Educação Rural considerava que, para os trabalhadores do campo, não era importante a formação escolar já oferecida às elites brasileiras". Esses autores (2007) acrescentam ainda que as "escolinhas" existentes no meio rural, quase sempre multisseriadas, ficavam isoladas do meio urbano e eram questionadas pelas classes hegemônicas sobre a eficácia do ensino que ministravam.

Em função desse imaginário social, os trabalhadores do campo também achavam que para melhorar de vida, ou mesmo para estudar, precisavam se mudar para a cidade ou mandarem os seus filhos em busca de melhores oportunidades, pois ali, no meio rural, havia poucas condições de desenvolvimento e formação dos jovens.

Destarte, Munarim (2008) observa que a Educação Rural vem sendo tratada de forma excludente e tem sido usada como instrumento de domesticação dos povos que vivem no campo. Para Rocha, Passos e Carvalho (1998, p. 3),

[...] a educação para a população do meio rural, nunca tivera políticas específicas, o atendimento a educação se deu através de campanhas, projetos e/ou políticas compensatórias, sem levar em conta as formas de viver e conviver dos povos do campo, que ao longo da história foram excluídos enquanto sujeitos do processo educativo. 
Nesse sentido, Azevedo, Souza e Almeida (2007, p. 74) destacam [...] "a importância do embate dos movimentos sociais do campo, que desencadearam uma luta organizada, exercendo pressão sobre as forças políticas [...]”. Esses autores (2007) acrescentam ainda que os movimentos sociais do campo passam a inserir na pauta de reivindicações o direito à educação traduzida, posteriormente, no ideário “Por uma Educação do Campo”. Esse ideário se traduz numa educação para a população do/no campo, com ações educativas que possam incorporar os espaços da floresta, da pecuária, das minas e da agricultura, fundamentando-se nas experiências e práticas sociais que constituem as populações e seus conhecimentos, habilidades, sentimentos, valores, modo de ser e produzir, de se relacionar com a terra e formas de compartilhar a vida (ROCHA; PASSOS; CARVALHO, 1998).

Antes do golpe militar, por volta dos anos 1961, instalou-se uma grande expectativa pela reforma agrária, em função das propostas de governo apresentadas por João Goulart, que assumiu o cargo de presidente do Brasil após a renúncia de Jânio Quadros. Com o golpe militar, o então presidente Marechal Castelo Branco promulgou a primeira Lei de Reforma Agrária do Brasil: o Estatuto da Terra, elaborado com o propósito de mexer com a estrutura fundiária no Brasil. No entanto, esta Lei não foi implantada e, de lá pra cá, grandes lutas e reivindicações vêm ocorrendo em prol desse propósito² ${ }^{2}$

Os anos de 1960, 1970 e 1980 foram marcados pela ação dos movimentos sociais também em outra frente: contra a ditadura instalada no Brasil. Em 1964, o movimento foi pela reforma na educação e pela organização dos órgãos sindicais. Ainda em 1964, as classes operárias reivindicavam a criação de escolas e bibliotecas públicas. Segundo Acilino e Lucini (2007), essas iniciativas das classes operárias foram “precursoras" para a consolidação de uma proposta de educação popular. Nesse período, houve uma preocupação em atrelar a prática do trabalhador ao conhecimento científico, consolidando “[ [...] um dos pilares que se desenvolverá na Educação Popular no Brasil, inaugurando uma política, na defesa de uma educação como prática social que será assumida pelos movimentos sociais, em diferentes momentos de nossa história" (ACILINO; LUCINI, 2007, p. 180).

Com o estabelecimento de uma educação popular nos anos 1960, Paulo Freire apresenta uma educação libertadora que, na visão de Acilino e Lucini (2007), incorpora-se ao movimento popular porque atende a esses grupos sociais, ao partir do que é vivido para propor uma transformação. Apresentam ainda que a

${ }^{2}$ www.mst.org.br 
[...] possibilidade de pensar a educação a partir das classes trabalhadoras, sob o princípio de uma educação que liberta e concebe a vida humana para além das desigualdades, por meio de um processo dialógico, tornou-se uma referência para pensar a educação popular (ACILINO; LUCINI, 2007, p. 181).

A absorção da proposta de Paulo Freire, nos anos 1960, pela Educação Popular foi um marco fundamental para os movimentos sociais, apesar da intensa repressão sofrida pelo povo brasileiro durante o período da ditadura, em que muitos movimentos sociais se desarticularam. Contudo, ela sobrevive e é incorporada como base na ação do movimento dos educadores populares.

Nesse contexto histórico de descaso do poder público com a Educação Rural, de falta de avanços sociais, políticos e econômicos para o campo, nos anos 1980 o Movimento dos Trabalhadores Rurais Sem Terra, ganha força com a realização do $1^{\circ}$ Encontro Nacional dos Trabalhadores Rurais Sem Terra, tornando-se um forte e importante movimento social, que além de lutar pela posse da terra e pela reforma agrária, tinham também como proposição a educação. E a Pedagogia de Educação Libertadora, proposta por Paulo Freire nos anos 1960, tornou-se um dos alicerces da Pedagogia do Movimento (ACILINO e LUCINI, 2007).

A luta dos sujeitos sociais do MST, suas ações e vivências alicerçaram a base para a constituição de uma nova visão política para a Educação Rural. Nessa direção, Munarim (2008) afirma que a luta pela reforma agrária constitui o marco histórico do "nascedouro" da Educação do Campo, "uma espécie de pano de fundo, de maternidade”.

Essa nova visão política para a educação desenvolvida nos meios rurais constitui-se como objeto de discussão dos sujeitos que a compõem, os educadores e camponeses, diferentemente de outros momentos em que a Educação Rural era objeto de discussão sem se considerar os sujeitos que nela atuam. Assim, a Educação Rural é reconfigurada e (re)nominada como Educação do Campo.

Contudo, ainda hoje, a educação destinada à população do meio rural permeia-se, em boa parte, pela negligência e descaso do Estado. Observa-se uma grande precariedade no funcionamento das escolas do meio rural, com pouca estrutura, currículos descontex tualizados, professores sem formação e com salários defasados. A formação da criança do meio rural era oferecida (e ainda é) de forma fragmentada.

A desigualdade de assistência do poder público entre o urbano e o rural é fortalecida na vida da população do campo, pelas diferenças sociais que foram alicerçadas na organização fundiária que historicamente marcou a estrutura social e econômica do Brasil. A posse de 
grandes propriedades rurais para poucos latifundiários foi uma das primeiras formas de organização rural que produziu tais desigualdades, e que ainda persistem.

Em 1988, aprovou-se a atual Constituição Brasileira, que apesar de não tratar diretamente da Educação do Campo, assegurou a educação como um direito das crianças e dos jovens brasileiros e dever do Estado, devendo ser ofertada nas instituições públicas para todos, sem distinção, possibilitando um novo olhar para a educação do/no meio rural. Essa visão da educação como direito de todos, apresentada pelos legisladores numa perspectiva de construção de uma sociedade democrática, demandou a necessidade de uma nova organização do sistema educacional brasileiro. Dessa forma, depois de um longo processo de construção e tramitação, a atual Lei de Diretrizes e Base da Educação Nacional n. 9394/96 (BRASIL, 1996) é aprovada e garante a oferta da educação básica pública para a população campesina, conforme as peculiaridades do campo, com adaptações específicas e necessárias para cada região.

\section{A Educação para os povos do campo na Legislação Educacional Brasileira}

A trajetória da educação para a população rural na legislação educacional não seguiu um percurso diferente do das constituições brasileiras. A primeira Lei de Diretrizes e Bases da Educação n. 4.024/1961 apesar de destinar três artigos para a educação rural exime o Estado de sua responsabilidade com a educação para a população campesina. No seu art. 32, a Educação Rural aparece como responsabilidade dos proprietários de terras, devendo estes manterem escolas para as crianças que morassem em suas terras, ou facilitar a frequência das mesmas em escola próxima. $\mathrm{O}$ art. 57 indicava que a formação dos profissionais para atuar no ensino rural poderia ser feita em estabelecimentos que promovessem a integração com o meio rural, não havia uma obrigatoriedade para que isso de fato ocorresse. A responsabilidade do Estado aparece de forma salutar somente no art. 105, ao responsabilizar o Estado a auxiliar serviços e entidades que mantivessem escolas rurais.

Por sua vez, a segunda LDB brasileira, a n. 5692/71, apesar de ter contemplado aspectos diferentes da lei anterior, não apresentou avanços significativos para a Educação Rural. No art. $4^{\circ}$, ela estabeleceu que os currículos da educação destinada ao meio rural deveriam atender as peculiaridades locais, no entanto não foi clara nesse propósito, dificultando assim o cumprimento dessa determinação. Um avanço em relação à LDB anterior aparece no art. 11, que se refere à adaptação do calendário escolar ao período de plantio e

colheitas, instituindo no $\S 2^{\circ}$ que "na zona rural, o estabelecimento poderá organizar os 
períodos letivos, com prescrição de férias nas épocas do plantio e da colheita de safras, conforme aprovado pela competente autoridade de ensino” (BRASIL, 1971).

A necessidade da formação de professores voltada para as especificidades do meio rural não foi objeto de atenção da segunda LDB. Ela apresentou no art. 29 apenas a necessidade de formação de professores voltada para as diferenças culturais regionais. Nos seus art. 49 e 51 , a responsabilidade com o financiamento da Educação Rural permanece com os proprietários de terras rurais, apresentando apenas uma alteração ao ampliar essa responsabilidade para as empresas voltadas para o trabalho rural.

A atual LDB (BRASIL, 1996) apresenta nos seus art. 26 e 28 uma nova maneira de se pensar a Educação Rural. De acordo com a referida Lei, o ensino do meio rural, precisa ser adaptado às condições específicas da realidade de sua população, com possibilidades para uma organização escolar voltada para a vida e a natureza do trabalho dos trabalhadores e trabalhadoras que ali vivem.

O art. 28 da LDB 9394/96 foi a mola propulsora para a elaboração do Parecer 36 (BRASIL, 2001) que institui as Diretrizes Operacionais para a Educação Básica das Escolas do Campo, e que determina:

art. 28. Na oferta da educação básica para a população rural, os sistemas de ensino promoverão as adaptações necessárias à sua adequação, às peculiaridades da vida rural e de cada região especialmente. I- conteúdos curriculares e metodologias apropriadas às reais necessidades e interesses dos alunos da zona rural; II - organização escolar própria, incluindo a adequação do calendário escolar as fases de ciclo agrícola e as condições climáticas; IIIadequação à natureza do trabalho na zona rural.

Esse novo olhar para a Educação do Campo foi fortalecido, também, nas Diretrizes Operacionais para a Educação Básica nas Escolas do Campo (BRASIL, 2002), sobre as quais a sua relatora (BRASIL, 2001, p.17) destaca a inovação do art. 28 da atual LDB (BRASIL, 1996), ponderando que:

[...] ao submeter o processo de adaptação à adequação, [a LDB] instituiu uma nova forma de sociedade no âmbito escolar em nosso país. Não mais se satisfaz com a adaptação pura e simples. Reconhece a diversidade sóciocultural e o direito à igualdade e à diferença, possibilitando a definição de diretrizes operacionais para a educação rural sem, no entanto, recorrer a uma lógica exclusiva e de ruptura com um projeto global de educação do país.

Considerando o alto índice de analfabetos e desescolarizados que ainda temos no campo e a necessidade de uma formação profissional para os jovens que lá estão, as Diretrizes 
significam uma conquista no âmbito das políticas públicas ao especificar que a Educação do Campo precisa ser ofertada para a população rural em todas as etapas, inclusive a Educação Profissional Técnica, que poderá ser oferecida integrada ao Ensino Médio, levando em consideração as especificidades da vida e trabalho destas pessoas. Delimita, assim, as diferenças entre o rural e o urbano, identificando e atendendo as especificidades de ser e de viver do homem do campo, criando uma identidade própria para as suas escolas e apontando para um caminho contrário ao das longas décadas de invisibilidade legislativa para a educação dos povos campesinos.

Outrossim, o art. 26 da LDB 9394/96 (BRASIL, 1996), que avança na organização curricular do Ensino Fundamental e Médio, contempla também a Educação do Campo, ao estabelecer que este currículo deve ser composto por uma “[ [...] base nacional comum a ser complementada em cada sistema de ensino e estabelecimento escolar, por uma parte diversificada, exigida pelas características regionais e locais da sociedade, da cultura, da economia e da clientela”. A proposta dessa LDB é que a diversidade seja respeitada, promovendo o acolhimento das diferenças sem transformá-las em desigualdades, apresentando uma organização específica para a população do campo. Desta forma, podemos sublinhar que a promulgação da nova LDB foi um marco para a Educação do Campo, que até então, não era contemplada na legislação com abrangência e olhar voltado para as necessidades específicas da população campesina.

Nos anos 1990, no bojo dessas legislações e da intensificação dos movimentos reivindicatórios do campo, outras importantes ações e conquistas marcam esta História, como o I ${ }^{\circ}$ Encontro Nacional de Educadoras e Educadores na Reforma Agrária (I ${ }^{\circ}$ ENERA), realizado em julho de 1997, e a I ${ }^{a}$ Conferência Nacional por uma Educação Básica do Campo, em 1998, onde educadores, grupos organizados e lideranças governamentais começaram a pensar um projeto educacional e político de educação para a população do campo.

Uma vez mais, as lutas e reivindicações dos movimentos sociais pela educação, especialmente pelo MST, estabelecem um divisor de águas, marcando um novo rumo para a Educação Rural: uma Educação do Campo, que estabelece um novo olhar para o meio rural, concebendo esse espaço como lugar de produção de vida em todos os aspectos.

A Educação do Campo não trata de uma nova modalidade de educação, e sim, um movimento social que luta por políticas públicas que possam assegurar à população do campo, o direito a todas as etapas da educação básica, e formação profissional com currículos e 
metodologias apropriadas aos interesses e necessidades dos alunos do meio rural, respeitando e valorizando suas experiências e modo de vida.

A Educação do Campo é um movimento social que cada vez mais vem conquistando espaço na agenda das políticas públicas brasileiras, em função da ação dos movimentos sociais. O "dos" aqui, significa que o MST foi fundamental para o início desse movimento denominado de Educação do Campo, mas que, no entanto, não foi o único. Outros não menos importantes movimentos sociais envolveram-se nas lutas em prol dessa causa, que apesar de serem muitos, vale a pena citar: Movimento dos Atingidos pelas Barragens (MAB), Movimento das Mulheres Camponesas (MMC), Movimento dos Pequenos Agricultores (MPA), sindicatos de trabalhadores rurais e federações estaduais desses sindicatos vinculados à Confederação dos Trabalhadores da Agricultura (CONTAG), Movimento de Mulheres Trabalhadoras Rurais ${ }^{3}$ - vinculado à CONTAG, a Rede de Educação do Semiárido Brasileiro (RESAB), além de uma série de outras organizações de âmbito local (MUNARIM, 2008).

Nessa perspectiva, a Educação do Campo não se constitui somente numa modalidade de educação, mas num movimento político que luta em prol de um novo modo de pensar a educação para o povo brasileiro que vive do e trabalha no campo. Essa concepção de Educação defende uma escola que não seja urbanocêntrica, que possibilite a construção de conhecimentos potencializadores de modernas técnicas de agricultura, novas tecnologias de produção econômica que propiciem condições de interpretação da realidade, baseada nas relações de trabalho e na vida a partir de estratégias solidárias, que garantam a melhoria da qualidade de vida dos que vivem e sobrevivem no e do campo, e, consequentemente, nas cidades.

\section{Educação do Campo enquanto política pública: processo de constante apropriação}

Para compreendermos a constituição da Educação do Campo como política pública de Estado e/ou de governo, recorremos à teoria de Azevedo, Souza e Almeida (2007) de que as políticas públicas são constituídas por cinco fases, a saber: agenda, formulação, tomada de decisão, implementação e avaliação. A agenda é a definição da política e das questões que a permearão; a formulação consiste na construção de parâmetros, alternativas e ações para a implantação. A fase de implementação compreende o desenvolvimento das ações que colocam em prática o que foi discutido, proposto e formulado. A última fase é imprescindível a todo o

\footnotetext{
${ }^{3}$ Este movimento sustenta a chamada "Marcha das Margaridas", que propõe uma reflexão sobre a vida e as condições de trabalho das mulheres do campo e da floresta.
} 
processo, pois é com a avaliação que se identifica se as ações propostas foram realmente executadas, além de permitir identificar avanços e ou necessidades de ajustes nas políticas públicas.

Sobre a primeira fase, a da agenda, Azevedo, Souza e Almeida (2007, p. 5), inspirados em Arroyo e Fernandes (1999) e Kolling (2002), sublinham que

\begin{abstract}
a luta e as articulações dos movimentos sociais do campo, a partir de 1997, incluíram debates específicos na agenda oficial, a fim de formular e implementar políticas públicas de educação, considerando as necessidades e as especificidades dos sujeitos desse setor, isto é, a política de Educação do Campo.
\end{abstract}

A fase de formulação das políticas públicas para a Educação do Campo foi uma etapa que, segundo Azevedo, Souza e Almeida (2007, p. 5), “[ [...] consistiu na organização e realização de Seminários Nacionais, Regionais e Estaduais, na articulação e parceria dos movimentos sociais e sindicais com instituições governamentais e não-governamentais”. Dessa articulação, resultou entre outras iniciativas a elaboração da coleção "Por uma Educação do Campo", e do Parecer do Conselho Nacional de Educação n. 36/2001, que serviu como base para a organização das Diretrizes Operacionais para a Educação Básica nas Escolas do Campo, instituída pelo Ministério da Educação em 2002, conforme abordado anteriormente.

Nesse processo de construção de uma política pública educacional, as fases de implantação e implementação são cruciais para que o que foi formulado ganhe materialidade. O papel exercido pelos órgãos gestores, professores e comunidade escolar possibilitará ou não a sua concretização. A garantia do cumprimento das propostas por uma legislação, oriunda de uma demanda social, que foi conquistada por uma longa luta de um segmento da sociedade que busca por condições de igualdade, atravessa processos de negociação, administração de conflitos e iniciativas do poder público, no sentido de promover ações que viabilizem condições para a sua efetiva implementação. E se nas fases anteriores, a pressão e a participação popular são imprescindíveis, aqui elas tornam-se vitais.

O início de uma política pública apresenta uma perspectiva que se abre à sociedade. Essa etapa denomina-se implantação. Nessa fase, de modo geral, “[ [...] a regulamentação do que está proposto pela política ou pela legislação dela decorrente ainda se encontra em debate e dependente da análise das condições que dificultam ou facilitam essa fundação [...]” (GOMES, 2012, p.26). Essas condições passam pela canalização de recursos específicos para o que está sendo proposto, estabelecimento de parcerias com a sociedade civil, apoio políticos e identificações de possíveis tensões para saná-las. As tensões se manifestam no 
estabelecimento das prioridades nos investimentos dos recursos públicos, e nesse processo a luta dos movimentos sociais continua no sentido de pressionar o poder público para direcionamento de recursos para a implementação das políticas de Educação do Campo.

Como decorrência dessa fase inicial vem a capacidade de implementação da política, da execução de um plano, programa ou projeto que se instaure na realidade por meio de providências concretas. É um processo que representa o desafio de transformar as históricas desigualdades sociais, culturais e educacionais vivenciadas pela população campesina em nosso país. Assim, o que se apresenta é que entre a legislação, as políticas públicas e a vida social há um grande percurso a ser trilhado.

Nesse sentido, as ações do poder público, dos movimentos sociais, das universidades e dos sujeitos do campo são de fundamental importância para a superação dos desafios que erigem nessa fase. A principal ação do Estado está no financiamento dos programas e projetos, sendo necessário o reconhecimento das diferenças no custeio por aluno que estuda no campo, em função das necessidades específicas das suas múltiplas realidades. Conforme estabelecido nas Diretrizes Operacionais (BRASIL, 2002), art. 15, a observância na oferta do ensino em todas as etapas da Educação Básica, custeado pelo poder público, necessita de especial atenção para a relação professor/aluno, que nesse caso será diferente do custeio para o aluno do meio urbano. As escolas do campo concentram um número relativamente menor de alunos e isso precisa ser considerado. Portanto, o valor do Fundo de Manutenção e Desenvolvimento da Educação Básica e de Valorização dos Profissionais da Educação - FUNDEB a ser destinado aos alunos do meio rural precisa ser diferenciado, ou seja, precisa ser um valor maior que o estabelecido em nível nacional, que atualmente abrange o urbano e o rural. Salienta ainda o referido artigo, a importância de uma remuneração digna com a inclusão de planos de carreira e programas de formação continuada para os profissionais da educação.

Aos movimentos sociais que se ocupam da Educação do Campo cabe o acompanhamento das demandas das populações campesinas e das suas escolas, para reivindicar junto aos órgãos públicos o devido acolhimento e cumprimento da legislação, devendo inclusive, abrir novos espaços na fase de agenda, quando outras demandas forem detectadas, conforme previsto nas Diretrizes Operacionais (BRASIL, 2002).

Às universidades cabe promover a oferta de cursos para formação de professores voltados para a realidade específica do campo, com metodologias e propostas educacionais que atendam às peculiaridades desse meio, observando: 
art. 13. [...] I - estudos a respeito da diversidade e o efetivo protagonismo das crianças, dos jovens e dos adultos do campo na construção da qualidade social da vida individual e coletiva, da região, do país e do mundo; II - propostas pedagógicas que valorizem, na organização do ensino, a diversidade cultural e os processos de interação e transformação do campo, a gestão democrática, o acesso ao avanço científico e tecnológico e respectivas contribuições para a melhoria das condições de vida e a fidelidade aos princípios éticos que norteiam a convivência solidária e colaborativa nas sociedades democráticas (BRASIL, 2002).

E por fim, aos sujeitos do campo, protagonistas ímpares neste cenário, cabe o papel de valorizar a cultura do campo, o meio em que vivem e, principalmente, a conscientizarem-se da sua responsabilidade e comprometimento com a construção da escola do campo voltada para as especificidades locais, onde as instituições, as famílias e as comunidades trabalhem pelo desenvolvimento do meio; participarem ativamente dos movimentos e da vida das escolas; garantirem os espaços de discussão e tomada de decisões sobre a escolarização dos seus filhos; apropriarem-se da vida e do entorno da escola.

A criação e implementação de programas e projetos voltados especificamente para atendimento aos trabalhadores do campo são resultados concretos desse trabalho conjunto entre movimentos sociais, universidades e sujeitos do campo, tais como o Programa Nacional de Educação na Reforma Agrária - PRONERA, e de instituições de ensino com metodologia sustentada pela Pedagogia da Alternância, como as Casas Familiares Rurais - CFR, as Escolas Famílias Agrícolas - EFA.

O PRONERA foi criado a partir das pressões advindas do I Encontro Nacional de Educação na Reforma Agrária (ENERA), e representa uma proposta de política pública específica de Educação de Jovens e Adultos em áreas de reforma agrária e de Educação do Campo, pelo governo federal.

As EFA e as CFR foram implantadas no Brasil na década de 1960, com base em experiências exitosas na França. As EFA são escolas voltadas para o atendimento de jovens oriundos de famílias que exercem atividades profissionais ligadas ao setor agropecuário. Portanto, formam os filhos de pequenos proprietários rurais, e têm como proposta educacional a Pedagogia da Alternância, que adequa a realidade escolar à dos alunos, pressupondo que o primeiro ambiente de aprendizagem do aluno é o familiar e a sua realidade. A escola é o local onde "o educando compartilha os múltiplos saberes que possui com os demais atores, de maneira reflexiva e, finalmente, aplica o conhecimento e a prática na comunidade agrícola ou faz uso delas em movimentos sociais" (CHAVES; FOSCHIERA, 2014, p. 07). Nas EFA, o Ensino Fundamental do $6^{\circ}$ ao $9^{\circ}$ ano acontece de forma seriada, com duração de quatro anos, sendo o período de alternância de quinze dias na propriedade, considerado como "tempo 
família”, e quinze dias na escola, "tempo escola”, com formação técnica e intelectual. A União Nacional das Escolas Famílias Agrícolas do Brasil (UNEFAB) foi criada em 1982, com o objetivo de representar e assessorar essas escolas, fortalecendo a implementação e divulgação da Pedagogia da Alternância.

As Casas Familiares Rurais são instituições de ensino que funcionam em parceria com o Estado e órgãos privados que buscam alternar a realidade familiar dos alunos com o processo de ensino. As CFR, geralmente, são administradas pelas comunidades agrícolas, por meio de um Conselho de Administração eleito pela Associação Regional das Casas Familiares Rurais ARCAFAR (WEIRICH NETO; VISBISKI, 2004).

Por sua vez, nas CFR a segunda etapa do Ensino Fundamental é ofertada em regime de suplência num período de três anos, e o período de alternância é de uma semana na escola e duas semanas em casa, onde os alunos anotam todas as atividades realizadas, para apresentação e discussão posterior, na escola. Nessas instituições prevalece a formação técnica do agricultor (QUEIRÓZ, 1997).

Nascimento (2005, p. 24) observa que:

no Brasil, ao conjunto de EFAs e CFRs convencionou-se chamar de CEFAS Centros Familiares de Formação por Alternância. Entre outros objetivos os centros surgem como uma possibilidade de educação apropriada às necessidades sociais e históricas a fim de minimizar o êxodo, desenvolver o campo, superar as condições de pobreza, abandono, entre outras mazelas existentes no campo, através de uma formação conscientizadora dos jovens e suas famílias junto às comunidades.

Segundo Chaves e Foschiera (2014), a partir de dados da UNEFAB (2014), no Brasil existiam, em 2014, 263 CEFAS, com 23.524 pessoas em formação com o envolvimento de 74.000 famílias. Grande parte dos CEFAS se concentra na região sul do país.

Na última fase, a da avaliação das políticas públicas, faz-se necessário analisar a efetivação dos programas implementados, os resultados alcançados, as dificuldades enfrentadas e se os objetivos estabelecidos estão sendo realizados. Na Educação do Campo, essa avaliação perpassa pela observância do cumprimento das determinações postas na legislação, em especial pelas Diretrizes Operacionais para a Educação Básica das Escolas do Campo (BRASIL, 2002), pelos diversos órgãos públicos. Nesse sentido, importa constatar se a prática pedagógica realizada nas escolas do campo está atendendo às reais necessidades do sujeito que vive do e no campo. Importar analisar se os preceitos de educação constantes na atual Constituição Federal (BRASIL, 1988), na LDB (BRASIL, 1996) e nos preceitos básicos da Educação do Campo estão se realizando nas realidades escolares dos sujeitos do campo. 
Avaliar uma política pública, portanto, pode ser entendida, também, como um processo de permanente discussão, implicando na retomada das ações estabelecidas, ou na construção de novas agendas.

\section{Considerações Finais}

A Educação do Campo emerge como um movimento contra-hegemônico em um contex to histórico de ausência de investimentos do poder público com a educação voltada para esse segmento da população brasileira. Os desafios sempre foram e ainda são muitos. Assim a luta e reivindicação dos movimentos sociais por uma educação do e no campo, entendendo esse espaço, como lugar de produção de vida em todos os aspectos, constitui um marco referencial para o estabelecimento de políticas públicas para mudança desse cenário. A criação de programas como o PRONERA, as EFA e as CFR são ações concretas no âmbito das políticas públicas para a população do campo. No entanto essas ações atingem uma parcela ainda muito pequena dessa população.

No campo legislativo, a atual LDB (BRASIL, 1996) e as Diretrizes Operacionais para a Educação Básica do Campo (BRASIL, 2002) se configuram como representantes de uma proposta de educação que evidencia as diferenças entre o rural e o urbano, identificando e atendendo às especificidades de ser e de viver do homem do campo, reconhecendo as identidades que sustentam as escolas do meio rural. Contudo, mesmo avanços consideráveis da legislação brasileira, muitas realidades das escolas voltadas para a população rural seguem acumulando uma série de precariedades, indicando que a fase de implementação de uma política pública é um campo de disputas e tensões por serem vencidas, e que reclama a atenção e a ação constantes dos movimentos sociais e dos sujeitos do campo.

\section{Referências}

ACILINO, Antônio Clesio; LUCINI, Marizete. Ensinar e aprender na educação do campo: processos históricos e pedagógicos em relação. Cad. CEDES [online]. 2007, vol. 27, n.72 pp. 177195. ISSN 0101-3262.

AZEVEDO, Márcio Adriano de; SOUZA, Antonio Lisboa Leitão de; ALMEIDA, Luciane Soares. Concepções e processos das políticas públicas e a Educação do Campo: por uma escola de qualidade. 
BRASIL. Constituição Política do Império do Brazil, de 25 de março de 1824. Disponível em www.planalto.gov.br . Acesso em 20/04/2018.

. Constituição da República dos Estados Unidos do Brasil, de 24 de fevereiro de 1891. Disponível em www.planalto.gov.br. Acesso em 20/04/2018.

Constituição da República dos Estados Unidos do Brasil, de 16 de julho de 1934. Disponível em www.planalto.gov.br. Acesso em 20/04/2018.

.Constituição da República dos Estados Unidos do Brasil, de 10 de novembro de 1937. Disponível em www.planalto.gov.br. Acesso em 20/04/2018.

Constituição da República dos Estados Unidos do Brasil, de 18 de setembro de 1946. Disponível em www.planalto.gov.br. Acesso em 20/04/2018.

.Constituição da República da República Federativa do Brasil de 1967. Promulgada em 24 de janeiro de 1967. Disponível em www.planalto.gov.br. Acesso em 20/04/2018.

.Constituição da República da República Federativa do Brasil de 1988. Promulgada em 27 de novembro de 1988. Disponível em www.planalto.gov.br. Acesso em 20/04/2018.

.LDB nº024 \61. LDB - Lei de Diretrizes e Bases da Educação Nacional de 20 de dezembro de 1961. Disponível em www. planalto.gov.br. Acesso em 18/04/2018.

LDB n $5692 \backslash 71 . L D B$ - Lei de Diretrizes e Bases da Educação Nacional de 11 de agosto de 1971. Disponível em www.planalto.gov.br. Acesso em 18/04/2018.

Lei $n^{\circ}$ 9394/96. LDB - Lei de Diretrizes e Bases da Educação Nacional, de 20 de dezembro de 1996. Disponível em www.planalto.gov.br . Acesso em 18/04/2018.

. Ministério da Educação. Conselho Nacional de Educação. Parecer CNE/CEB nº36/2001. Diretrizes Operacionais para a Educação Básica nas Escolas do Campo. Brasília: $\mathrm{MEC} / \mathrm{CNE}, 2001$.

. Ministério da Educação. Conselho Nacional de Educação. Resolução CNE/CEB $\mathrm{n}^{\circ}$ 01/2001. Diretrizes Operacionais para a Educação Básica nas Escolas do Campo. Brasília: $\mathrm{MEC} / \mathrm{CNE}, 2002$.

.Resolução CNE/CEB, no 2/2008. Diretrizes Complementares, Normas e Princípios para o Desenvolvimento de Políticas Públicas de Atendimento da Educação Básica do Campo. Brasilia: $\mathrm{MEC} / \mathrm{CNE}, 2008$.

GOMES, Nilma Lino (Org.). Práticas pedagógicas de trabalho com relações étnico-raciais na escola na perspectiva da Lei no 10639/03. MEC, Brasília: Unesco, 2012.

MUNARIM, Antônio. Movimento nacional de educação do campo: uma trajetória em construção. In $31^{\text {a }}$ Reunião da ANPED, Caxambu, 2008. GT-03 Movimentos Sociais e Educação. Disponível em: 31 reuniao.anped.org.br. Acesso em 18/04/2018. 
NASCIMENTO, Claudemiro Godoy. A Educação camponesa como espaço de resistência e recriação da cultura: um estudo sobre as concepções e práticas educativas da Escola Família Agrícola de Goiás EFAGO. Dissertação de Mestrado em Educação (Políticas de Educação e Sistemas Educativos) da Universidade Estadual de Campinas. Campinas ,SP, 2005. Disponível em www.repositoriounicamp.br . Acesso em 26/07/2018.

ROCHA. Eliene Novaes; PASSOS, Joana Célia dos Passos; CARVALHO, Raquel Alves de. Texto Base Educação do Campo: Um olhar panorâmico. In I ${ }^{\mathrm{a}}$ Conferência Nacional da Educação do Campo. Luiziania/GO, 1998. Disponível em www.gepec.ufscar.br. Acesso em 15/04/2018.

QUEIRÓZ, João Batista. O processo de implantação da Escola Família Agrícola (EFA) de Goiás. Dissertação de Mestrado em Educação Escolar Brasileira da Universidade Federal de Goiás. Goiânia, GO, 2007. Disponível em www.ufg.br . Acesso em 26/07/2018.

VISBISKI, Vivieny Nogueira; NETO, Pedro Henrique Weirich. Casa Familiar Rural: uma escola diferente. Revista Extensão Rural, DEAER/CGExR - CCR - UFSM, ano XI, Jan-Dez de 2004. Disponível em: < www.ufsm.br> . Acesso em 26/06/2018. 